\title{
Voix du Contemporain. Histoire, mémoire et réel dans le roman français d'aujourd'hui, sous la direction de Gianfranco Rubino
}

\section{Stefano Genetti}

\section{(2) OpenEdition}

\section{Journals}

\section{Edizione digitale}

URL: http://journals.openedition.org/studifrancesi/9044

DOI: $10.4000 /$ studifrancesi.9044

ISSN: 2421-5856

\section{Editore}

Rosenberg \& Sellier

\section{Edizione cartacea}

Data di pubblicazione: 1 octobre 2008

Paginazione: 492-493

ISSN: 0039-2944

\section{Notizia bibliografica digitale}

Stefano Genetti, «Voix du Contemporain. Histoire, mémoire et réel dans le roman français d'aujourd'hui, sous la direction de Gianfranco Rubino», Studi Francesi [Online], 155 (LII | II) | 2008, online dal 30 novembre 2015, consultato il 10 janvier 2021. URL: http://journals.openedition.org/studifrancesi/9044 ; DOI: https://doi.org/10.4000/studifrancesi.9044

Questo documento è stato generato automaticamente il 10 janvier 2021.

\section{cc) (†) $\odot$}

Studi Francesi è distribuita con Licenza Creative Commons Attribuzione - Non commerciale - Non opere derivate 4.0 Internazionale. 


\title{
Voix du Contemporain. Histoire, mémoire et réel dans le roman français d'aujourd'hui, sous la direction de Gianfranco Rubino
}

\author{
Stefano Genetti
}

\section{NOTIZIA}

Voix du Contemporain. Histoire, mémoire et réel dans le roman français d'aujourd'hui, sous la direction de Gianfranco RUBINO, Roma , Bulzoni, 2006, pp. 229.

1 Memoria e testimonianza, passato e presente, Storia e storie, documentazione e narrazione, evento e invenzione: sono questi i territori esplorati negli atti del convegno tenutosi a Roma dal 9 all'11 dicembre 2004. Campo di indagine è la narrativa francese più recente, accomunata - per reazione ma anche sulla scia delle sperimentazioni succedutesi tra gli anni cinquanta e tutti gli anni settanta - dal ritorno al reale e al récit, termine che - nota il curatore nell'Avant-propos (pp. 9-12) - «menace sournoisement la pureté du roman comme genre de fiction» (p. 11). Sullo sfondo delle contaminazioni tra biofinzione, finzione critica e autofinzione, risaltano le ragioni, le modalità e gli effetti dell'iscrizione in letteratura del passato remoto o prossimo e del mondo odierno, dell'esperienza collettiva e del vissuto individuale - allo stesso tempo garanzia di aderenza alla realtà dei fatti e manifestazione del suo vacillare - in un'epoca in cui l'affidabilità della storiografia, così come dell'autobiografia, viene messa in discussione in quanto strumento conoscitivo e ripensata in termini appunto di costruzione narrativa.

2 Nell'intervento inaugurale, (Mémoire et imagination dans le roman français contemporain, pp. 13-33), quasi un giro di orizzonte che funge da inquadramento critico e storicoletterario delle questioni affrontate, Yves BAUDELLE sottolinea come la teorizzazione 
dell'anti-fiction, le contaminazioni biografiche e il successo riscosso dal romanzo storico concorrano a alimentare una visione spuria del genere romanzesco. Si susseguono poi approfondimenti monografici, paralleli tra due o più autori e contributi ad ampio raggio. Se in Mémoire et histoire(s) dans les romans d'Alain Nadaud (pp. 35-50) Rosa GALLI PELLEGRINI prende in esame strutture narrative e implicazioni metanarrative mostrando come dei polizieschi eruditi ambientati nell'antichità racchiudano una disincantata riflessione sulle falle della memoria e sul lavorio della scrittura, Matteo MAJORANO (Le Roman sans histoire, pp. 51-69) fornisce un'ampia panoramica editoriale sul romanzo storico dell'ultimo decennio prima di selezionare due esempi di R. Jauffret e J.-P. Dubois. A sua volta, Marie-Thérèse JACQUET (La Dernière guerre possible, pp. 71-84) mobilita due testi di P. Bergounioux - la ricognizione documentaria di Le Bois du Chapitre e la ricostruzione, tra fiction e diction, di B17G - e uno di immaginazione - Cris di L. Gaudé - al fine di sondare le strategie per mezzo delle quali l'autore - tramite e/o contro la finzione - si appropria di una guerra cui non ha preso parte. In analisi del tempo e dello spazio - le trasformazioni del tessuto urbano in particolare -, dei personaggi historiens e dei documenti citati si articola la lettura proposta da Gianfranco RUBINO di inchieste retrospettive costantemente ostacolate da oblio e occultamento (Détectives de l'histoire, histoires de détectives: Didier Daeninckx, pp. 85-96). Marc DAMBRE si sofferma invece sul respiro epico che attraversa la rievocazione delle gesta di un militante di estrema sinistra tra il Sessantotto e il Settantatre come un'aspirazione irrealizzabile, sintomo di una vertiginosa inquietudine identitaria (Une épopée paradoxale: "Tigre en papier" d'Olivier Rolin, pp. 97-110). In "Le pays où l'on n'arrive jamais". Enfance et mémoire dans l'œuvre de Patrick Modiano (pp. 111-123), Elisabetta SIBILIO evidenzia come l'autore demistifichi il paradiso dell'infanzia in quanto proiezione dell'adulto, metaforica compensazione di una memoria sfilacciata, mentre in Fictions $d u$ réel. Carrère, Ernaux, Daeninckx (pp. 125-140), Annie OLIVIER mette in rilievo la tensione tra vissuto e immaginazione confrontando tra loro L'Adversaire del primo, Passion simple della seconda e Je tue il... del terzo, testi che, oltre al dischiudersi della dimensione autobiografica al confronto con l'altro, comportano uno sdoppiamento autoriflessivo del racconto. Sullo spazio narrativo come teatro potenziale dove la voce - la parola operaia né monologante né dialogica - convoca il lettore-spettatore si concentra Dominique VIART in Théâtres de la fiction sociale. Autour de "Daewoo" de François Bon (pp. 141-161), saggio la cui portata si estende all'intera opera dell'autore risalendo anche alle analoghe esperienze di L. Kaplan o A. Filippetti. Alla narrativizzazione del discorso sociale si interessa anche Bruno BLANCKEMAN nella misura in cui getta le basi per lo studio del posizionamento, delle funzioni narrative e delle valenze estetiche di ciò che chiama Graphèmes (inscriptions du réel dans quelques récits au présent) (pp. 163-175). Si tratta di microtesti - classificati in sociografemi, etnografemi, psicografemi e filografemi o asserzioni scientifico-giuridiche - derivati dalla "vaste prose de société» (p. 164) cui attingono racconti, tra gli altri, di échenoz, Guibert e Houellebecq. Le Goût du détail (pp. 177-189) in quanto spia di un nuovo realismo minimalista è oggetto del discorso teorico di Grazia TAMBURINI: richiamando le critiche mosse da Robbe-Grillet a Balzac e rifacendosi a C. Ginzburg, ella riscontra nella poetica della minuzia concreta intesa come residuo, frammento di senso, un esito del declino di un modello epistemologico razionalistico e totalizzante cui subentra un paradigma indiziario, una visione parcellare e sempre congetturale della realtà.

3 Molto opportunamente è su alcune testimonianze di scrittori, di lingua francese e italiani, che questo confronto con la scrittura en train de se faire si chiude. A Tenter de 
mettre le réel en rythmes (une expérience personnelle) (pp. 191-199), dove Arno BERTINA medita sulla natura prismatica e respiratoria di ogni frase scandita dal ritmo dei ricordi, segue la sezione Dialogues d'écrivains (pp. 201-229), trascrizione del dibattito vivace soprattutto a proposito dell'eredità di «Tel Quel» - moderato da Arnaldo Colasanti e al quale hanno partecipato Marcello Fois e Didier Daeninckx, Cristina Comencini e Annie Ernaux, Elisabetta Rasy, Alessandro Piperno e Jacqueline Risset. Nei commenti degli studiosi come negli interventi degli autori, abbandono della finzione e rischio ovvero tentazione dell'inautenticità si alternano e interferiscono tra loro alla ricerca di un'adesione all'esperienza fissata e trasfigurata, perseguita e dilapidata mediante la scrittura. Su questa e altre contraddizioni caratteristiche della narrativa contemporanea il presente volume, per la molteplicità degli approcci e dei testi presi in considerazione, per l'alto livello e la coesione dei contributi, getta uno sguardo d'insieme atto a circoscrivere vari aspetti di una realtà letteraria sfuggente, imprendibile, in nome della presa - sempre precaria - che essa tenta di avere sul reale. 